\title{
A IMPORTÂNCIA DO ATENDIMENTO EDUCACIONAL ESPECIALIZADO NO DESENVOLVIMENTO PEDAGÓGICO DE CRIANÇAS COM TRANSTORNO DO ESPECTRO DO AUTISMO- TEA
}

\author{
Danilo Lima dos Santos \\ Glenda Silva Pinto Correia \\ Maria Eduarda Bezerra Pereira \\ Maria Fernanda Alves de Freitas \\ Diógenes José Gusmão Coutinho ${ }^{1}$
}

RESUMO: Neste trabalho será abordado a respeito da importância do atendimento educacional especializado no desenvolvimento pedagógico de crianças com Transtorno do Espectro do Autismo-TEA. Sendo a finalidade dissertar sobre a excepcionalidade que o suporte educacional, acompanhado de uma equipe estruturada e multidisciplinar favorece na educação da criança com autismo. Este Artigo dará ênfase ao progresso que a escola fornece na trajetória de alunos com alguma necessidade específica, como por exemplo, aqueles que possuem TEA. $\mathrm{O}$ favorecimento positivo que um atendimento educacional especializado e as suas políticas de uso e aplicabilidade apresentam será relatado através das relevâncias que uma sala de recursos multidisciplinar, unida a uma rede de funcionários habilitados e o apoio familiar podem proporcionar na aprendizagem pedagógica, moral e social dos discentes com autismo, uma vez que a educação especial produz resultados positivos e duradouros para toda a vida no indivíduo que dela usufrui. Além disto, apontar o surgimento do termo autismo e a contextualização discorrida do Atendimento Educacional Especializado- AEE baseado nas Diretrizes do Ministério da Educação como também mencionar pontos importantes no comportamento do docente perante situações de debates não articulados em sala sobre inclusão, aprimorando a vivência da turma através do desenvolvimento da criança com Transtorno do Espectro do Autismo.

Palavras-chaves: Educação. Autismo. Educação Especial. Atendimento Educacional Especializado. Inclusão.

ABSTRACT: This work will address the importance of specialized educational care in the pedagogical development of children with ASD-autism spectrum disorder. The purpose is to discuss the exceptionality that educational support, accompanied by a structured and multidisciplinary team, favors the education of children with autism. This Article will emphasize the progress the school provides in the trajectory of students with a

\footnotetext{
${ }^{\mathrm{I}}$ Doutor em Biologia Vegetal da UFPE. Atualmente Leciona disciplinas da área de Saúde no ensino técnico, tecnológico, graduação e pós-graduação. E-mail: gusmao.diogenes@gmail.com
} 
specific need, such as those with ASD. The positive favoring that a specialized educational service and its use and applicability policies present will be reported through the relevance that a multidisciplinary resource room, together with a network of qualified employees and family support can provide in the pedagogical, moral and social learning of the students with autism, since special education produces positive and lasting results for life in the individual who enjoys it. In addition, pointing out the emergence of the term autism and the contextualization discussed in Specialized Educational Service - AEE based on the Guidelines of the Ministry of Education, as well as mentioning important points in the teacher's behavior in situations of non-articulated debates in the classroom about inclusion, improving the experience of class through the development of the child with Autism Spectrum Disorder.

Keywords: Education. Autism. Special education. Specialized Educational Service. Inclusion.

\section{INTRODUÇÃO}

Este artigo apresenta como tema a importância do Atendimento Educacional Especializado-AEE no desenvolvimento pedagógico de crianças com Transtorno do Espectro Autista. Identificar e reconhecer a eficácia dos métodos adquiridos para melhor desenvolvimento dos alunos é fundamental no processo educacional.

A seleção do tema exposto deu-se pela observância das questões sociais que constroem o país e a ampla escassez de recursos. No recinto escolar, os impasses apresentados por alguns alunos com TEA é a resposta veemente da morosidade do poder público para as escolas, não apenas no fornecimento, mas também na fiscalização e demanda o que evidenciou pontos que antes se passava despercebido aos olhos, quando na verdade a dificuldade no desenvolvimento das crianças com autismo é proveniente do esquecimento social. Considerando que tal transtorno interfere no desenvolvimento social, a importância de detectar e trabalhá-lo durante o processo estudantil contribui, principalmente, para a auto-estima intelectual e social do aluno sendo fundamental para sua formação como cidadão, o que aponta a discursão de métodos específicos como imprescindível. 
Após argumentar sobre este estudo, a observância nos trouxe a reflexão acerca da seguinte questão: a importância do atendimento educacional especializado no crescimento social e intelectual da criança com TEA

A fim de responder à questão do artigo sobredito, apontamos o seguinte objetivo geral: Desempenhar com avidez os métodos abordados no curso de Educação Especial Inclusiva para o desenvolvimento dos alunos com TEA que estão em processo de formação.

Já os objetivos específicos são: Delinear a historicidade do autismo; elencando a necessidade do atendimento educacional especializado; Enfatizar a dimensão das técnicas do AEE e apontar a relevância que escola inclusiva produz na formação educacional e social da criança com Transtorno do Espectro do Autismo-TEA.

\section{PERCURSO METODOLÓGICO}

O percurso metodológico adotado neste estudo fez o uso de uma abordagem qualitativa. Segundo José Camilo Santos Filho (1995), a pesquisa qualitativa “... concebe o home como sujeito e ator, enfatizando a centralidade do significado como produto da interação social”. (SANTOS,1995, p.4I).

O procedimento de pesquisa utilizado no presente artigo parte de uma pesquisa bibliográfica. Para Antônio Joaquim Severino (2013), estudos bibliográficos “... é aquele que se realiza a partir do registro disponível, decorrente de pesquisas anteriores, em documentos impressos, como livros, artigos, teses, etc.”. (SEVERINO, 2013, p.I06). No intuito de aprofundar as discussões apresentadas recorremos à pesquisa campo. $\mathrm{Na}$ perspectiva de Antônio Joaquim Severino (2013), "a pesquisa é abordada no ambiente próprio para a pesquisa”. (SEVERINO,2013, p.107).

$\mathrm{O}$ instrumento de coleta de dados utilizados foi a observação. De acordo com Marina de Andrade Marconi \& Eva Maria Lakatos (1999) a observação “... utiliza os sentidos na obtenção de determinados aspectos da realidade. Consiste em ver, ouvir e examinar fatos ou fenômenos”. (MARCONI; LAKATOS,1999, p.90). 
O lócus da pesquisa foi uma Escola Municipal, Recife-PE, nas turmas de Educação Infantil e de Ensino Fundamental respectivamente. Com estrutura e respaldo para o desenvolvimento dos alunos, no entanto com ausência de recursos eficazes para a desenvoltura da temática abordada.

\section{FUNDAMENTAÇÃO TEÓRICA}

\section{A IMPORTÂNCIA DO ATENDIMENTO EDUCACIONAL ESPECIALIZADO NO DESENVOLVIMENTO PEDAGÓGICO DE CRIANÇAS COM TRANSTORNO DO ESPECTRO DO AUTISMO- TEA.}

O nascimento de uma criança sempre gera muitas expectativas para a mãe e família. Atualmente, através do pré-natal, com ultrassonografia e outros exames já é possível acompanhar a formação do bebê no útero da mãe, para saber se está tudo em ordem ou se há algum problema. Quando algo é detectado, ainda no pré-natal, fica mais fácil buscar uma cura e ter mais orientações médica. Após o nascimento, a família acompanha o desenvolvimento da criança e geralmente os pais esperam que seja dentro do padrão que a maioria da sociedade julga normal. Quando isso não acontece, vindo a criança a não conseguir realizar atividades esperadas para o seu desenvolvimento como: não acompanhar com os olhos movimentos de objeto, não se assustar com barulho muito alto ou não suportar barulhos; não andar; não falar e se isolar das pessoas, entre outros, causa na família, uma certa frustação passando a observar mais a criança, para ter a certeza de que se faz necessário a ajuda de médicos e especialistas para dar um diagnóstico clínico específico.

De acordo com o MEC:

O Ministério da Educação, por intermédio da Secretaria de Educação Especial, considerando a Constituição Federal de 1988, que estabelece o direito de todos a educação; a Política Nacional de Educação Especial na Perspectiva da Educação Inclusiva, de janeiro de 2008; e o Decreto Legislativo no 186 , de julho de 2008, que ratifica a Convenção Sobre os Direitos das Pessoas com Deficiência (ONU, 2006), institui as Diretrizes Operacionais da Educação Especial para o Atendimento Educacional Especializado - AEE na educação básica, 
regulamentado pelo do Decreto no 6.571, de 18 de setembro de 2008 . (BRASIL,2008, p. 13)

A instituição das diretrizes operacionais da educação especial para o atendimento educacional especializado na educação básica regulamentado pelo MEC, contribuiu para um grande avanço nos marcos legais e princípios pedagógicos, da igualdade, de condições de acesso à participação em um sistema educacional inclusivo. As diretrizes conduzem as escolas em sua organização e planejamento de trabalho. O Programa Atendimento Educacional Especializado é uma política pública direcionada a estudantes que têm necessidades específicas de aprendizagem. Segundo o MEC, "a educação especial é uma modalidade de ensino que perpassa todos os níveis, etapas e modalidades...” (BRASIL, 2008, p. 16). Isso significa dizer que o estudo na educação básica estar assegurado à criança autista, assim como o atendimento educacional especializado. Esse atendimento complementa a formação do aluno com vista na autonomia e independência na escola e fora dela. São serviços e recursos da educação especial àqueles que asseguram condições de acesso ao currículo por meio da condição da acessibilidade aos materiais didáticos, aos espaços e equipamentos, aos sistemas de comunicação e informação e as atividades escolares. Os pais ou responsáveis por criança diagnosticada com TEA devem matricular na escola comum do ensino regular, a qual deve ofertar o atendimento educacional especializado - AEE, promovendo o acesso e as condições para uma educação de qualidade. Sob essa circunstância, a necessidade de compreensão acerca do termo autismo na finalidade de compreender o porquê do surgimento do termo Autista e principalmente entender a importância do acompanhamento. Levando em consideração o início da formação social, que quaisquer indivíduos que apresentasse padrões comportamentais era, consequentemente apontado como louco, especificamente esquizofrênico, uma vez que qualquer pessoa que obtivesse alguma diferença no padrão, era caracterizado e recluso do convívio social, sendo considerado muitas vezes como alguém incapaz de viver em sociedade. Neste "círculo a parte" faziam parte crianças, jovens e adultos com necessidades específicas que recebiam a rotulação geral de esquizofrênicos sem nenhum laudo clínico processual que comprovasse. Após isso, Leo Kanner, que participou de um estudo 
observatório de II crianças "esquizofrênicas" onde, tal tese foi derrubada após compreender que as crianças em estudo não tinham um comportamento padrão de pessoas esquizofrênicas, retificando o termo e criando assim, a definição de autismo, que vem do Grego "autós" que significa por si mesmo. Durante esta fase, muitos cientistas creditavam que o autismo era proveniente da mãe, ou seja, congênito; tal posicionamento foi derrubado como tanto outros que resultaram no reconhecimento do Transtorno do Espectro Autismo como um distúrbio em 1968 e, apenas em 1993 entraram para a Organização Mundial de Saúde- OMS. Ou seja, a importância dos estudos a cerca, do TEA são as ferramentas crucias para o desenvolvimento do Atendimento Educacional Especializado, na qual detém em sua formação a função de aprimorar a aprendizagem do indivíduo com autismo e seu convívio social, uma vez que é um dos marcos deste transtorno é a dificuldade no convívio social, que é variável obtendo inúmeros graus. Sabese que o TEA manifesta e se desenvolve de formas diferentes em cada caso Mello (2004, p.II4-II5), caracteriza a tríade de dificuldades que seriam as manifestações comuns causadas pelo autismo, são elas:

(...) Dificuldade de comunicação - caracterizada pela dificuldade em utilizar sentido todos os aspectos da comunicação verbal e não verbal. (...) Dificuldade de sociabilização - este é o ponto crucial no autismo e o mais fácil de gerar falsas interpretações. (...) Dificuldade no uso da imaginação - se caracteriza por rigidez e inflexibilidade e se estende às várias áreas do pensamento, linguagem e comportamento da criança. Exemplo: comportamentos obsessivos e ritualísticos.

É preciso ser trabalhado cada área de dificuldade apresentada pela criança autista, seja na comunicação, na socialização ou no uso da imaginação há características comuns ao quadro geral, mas também únicas de acordo com cada pessoa. Não existe uma fórmula para ensinar crianças com TEA. Hoje, os especialistas em educação já sabem: mesmo que duas pessoas apresentem o mesmo diagnóstico, elas podem reagir de modos diferentes a uma mesma proposta pedagógica. Por isso, o que funciona para um estudante com autismo pode não funcionar para outro. Assim as intervenções devem ser analisadas individualmente por toda a equipe multidisciplinar que acompanha o caso. Para ensinar uma criança com autismo, o professor não precisa ser especialista no transtorno, porém o 
mesmo deve ter ao menos, uma noção sucinta acerca de como aprimorar suas táticas educacionais para trabalhar com. Além disto, é importante que procure conhecer todos os alunos de forma individual tendo também um olhar atento ao processo como cada um aprende na tentativa de enriquecer a aplicabilidade das atividades no recinto escolar. Mais do que um conhecimento específico, a inclusão dessas crianças requer uma mudança na política da escola e como ela faz educação. É através dessa necessidade que a escola inclusa adentra nas questões educacionais especializadas, tendo em vista que um dos maiores pontos de obstáculos existentes em crianças com TEA é a dificuldade na socialização, na qual interfere de forma direta no progresso pedagógico da criança com autismo. É exatamente por essa questão, que se encontra a necessidade de um espaço capaz de fornecer um suporte maior ao avanço intelectual do indivíduo.

A educação que inclui, é aquela que obtém uma estrutura adaptativa na função de introduzir a criança ao meio pedagógico na finalidade de enfrentar os obstáculos que o transtorno apresenta e ultrapassar as barreiras sociais através da inclusão, principalmente na escola, onde é o ambiente que a criança tem maior acesso a variabilidade de raças, pessoas, etnias e entre outros que favorece seu aprendizado. $O$ ensino que possibilita educar de forma inclusiva, segundo Melo, Lira e Facion (2008, p.65), [...]

[...] impõe a construção de um projeto que não se dará ao acaso nem de uma hora para outra e que não é uma tarefa individual. Ao contrário, trata-se de um trabalho coletivo, que envolve discursões e embates entre diferentes esferas (governo, sociedade, escola e indivíduo) em que seja possível refletir sobre que escola queremos construir e que indivíduos pretendemos forma.

A magnitude que a escola inclusiva proporciona ao desenrolamento da criança com TEA é explicito quando a mesma apresenta um avanço no comportamento interacional engajado ao avanço social e o educacional também. No entanto, a equipe multidisciplinar vem a ser o ponto que interliga o social ao educacional, estabilizando uma ponte como um meio de contingência capaz fornecer a criança com TEA uma vida tranquila e saudável.

Ainda assim, vale ressaltar que a escola inclusiva não é referente apenas a uma equipe multidisciplinar ou a uma sala de atendimento educacional especializado. Ela é relativa de acordo com toda a organização que a instituição de ensino tem como por 
exemplo o espaço, a equipe, instrumentos de trabalho específicos como também, um sistema operacional, um corpo docente ativo que interaja com a criança e suas respectivas necessidades tanto fisiológicas, educacionais e sociais. Um parque que ofereça atividades sensoriais em grupo; materiais didáticos que sejam direcionados para os autistas e entre outros utensílios, fazem parte do conjunto de itens imprescindíveis para a formação da criança com Transtorno do Espectro Autismo que, infelizmente são escassos em muitas escolas públicas e privadas, o que atrapalha toda a rede multidisciplinar a avançar na educação. Apelar para a contextualização da teoria é o maior contratempo existente no período hodierno uma vez que, o Ministério da Educação já forneceu as principais diretrizes que uma escola inclusiva deve ter para que o desenvolvimento pedagógico ocorra. Contudo, a morosidade do governo para a educação enfatiza ainda mais as dificuldades dos casos, travando toda a metodologia abordada e reformulada pela equipe.

Isso significa que o momento pede a prática e não mais teoria visto que, já se tem norteamento acerca de como trabalhar com essa demanda dos discentes. A partir deste critério, o analise sob as devidas condições de trabalho e resultado desejado possuem uma variação exorbitante oriunda, única e exclusivamente, do descaso. Se comparado, a estrutura educacional das escolas particulares com a rede de pública de ensino, a disparada de vantagem não vem apenas na organização sistemática das práticas de aprendizagem como também, principalmente, da inevitável ausência de recursos mínimos que uma sala de Atendimento Educacional Especializado deve ter. Seguindo esta lógica, se faz necessário o esclarecimento do que é uma sala de AEE. Segundo o site Instituto Paradigma (2013, p. 32):

\footnotetext{
As salas de recursos multifuncionais são ambientes dotados de equipamentos, mobiliários e materiais didáticos e pedagógicos para a oferta do atendimento educacional especializado que tem como objetivos: Prover condições de acesso, participação e aprendizagem no ensino regular aos alunos com deficiência, transtornos globais do desenvolvimento e altas habilidades ou superdotação, matriculados na rede pública de ensino regular.
}

Rica em materiais que possam suprir os requisitos do planejamento pedagógico, as Salas de Recursos Multifuncionais são fundamentais para o aprimoramento daquilo aprendido na sala de aula como também na tentativa de desenvolver as habilidades sociais 
do indivíduo por meio de brincadeiras e atividades orientadas. $\mathrm{O}$ objetivo é totalmente alcançável por meio de uma sala bem equipada. Visando já a dificuldade em agregar rapidamente tais equipamentos, o MEC desenvolveu um programa que facilitasse a implantação das ferramentas do AEE, tendo em vista a demanda organizacional, ou seja, como são instrumentos diferenciados, a atenção na aplicabilidade, uso e conservação possui todo um guia, assegurando uma maior durabilidade dos equipamentos. Além de garantir uma maior avidez no processo de organização da estrutura escolar para o recebimento deste espaço enriquecedor, o Programa de Implantação da Sala de Recursos Multifuncionais estabelecido pelo Ministério da Educação, traz consigo uma planilha de documentos que viabilizam a aplicação mais rápida do AAE no recinto institucional. Assim como, meios de conceder materiais variados mediante doações que ocorrem de forma corporativa.

Segundo o MEC:

A doação dos itens se configura em entrega de bens do patrimônio público para guarda e cuidados dos beneficiários. O Contrato de Doação dos bens das salas de recursos multifuncionais é formalizado pelo Ministério da Educação por meio da Secretaria de Educação Especial/SEESP, que encaminha em três vias para assinatura do titular da Secretaria de Educação, estipulando prazo de 30 dias para seu retorno." (BRASIL,2012, p. 54).

A organização oferece uma segurança e traz benefícios múltiplos entre quem doa e o governo sendo uma ponte para o aprimoramento das relações comerciais entre empresas privadas, pessoas físicas e demais instituições. Tal ação proporciona ao governo uma linha imediata de constatações que precisam destas ferramentas já presentes que, no entanto, precisam ser distribuídas para as escolas estaduais e municipais desprovidas desses materiais.

Os instrumentos são diversos, dentre eles estão os apetrechos tecnológicos informativos, livros em Braille, alfabeto em LIBRAS, jogos para a inclusão, Material dourado, Sistema corporal tátil, sequência numérica em relevo, dados e bingos em libras e em Braille, tapete monta e desmonta e entre outros. A lista é gigante e exercem suma importância no percurso pedagógico que, trazendo para a realidade das crianças com TEA, 
estimulam a parte cognitiva, sensorial e comunicativa tendo em vista que crianças com autismo têm dificuldade na fala, são hiperativas, agressivas, se irritam com facilidade e são extremamente sensíveis ao som. Essas dificuldades são características enfáticas na preocupação que se deve ter com o acompanhamento na Sala de Recursos, sendo fundamental o silencio e a tranquilidade no espaço durante todo o do atendimento.

Em conformidade das diretrizes (BRASIL, 2009 Decreto nº 13/2009), Para atuação no AEE, o professor deve ter formação inicial que o habilite para o exercício da docência e formação específica na educação especial, inicial ou continuada. A formação e atualização do professor que atua AEE são importantíssimas, pois propiciam conhecimentos das características gerais da criança com TEA. Esses conhecimentos afloram sob as estratégias de trabalho. A partir do momento que há conhecimento do ser, as possibilidades de interação e condução da criança a novos horizontes de aprendizagem são ampliadas. Além disso, ajuda na articulação com o professor da sala regular e demais comunidade escolar para que flua com tranquilidade e concordância no que diz respeito às orientações inclusivas e de acessibilidade.

Não se pode esquecer que a oferta do atendimento educacional especializado - AEE deve constar no Projeto Pedagógico da escola de ensino regular, organizado em uma sala de recursos multifuncionais. $\mathrm{O}$ atendimento à criança deve ocorrer no contra turno e que se torna fruto de muitas especulações entre muito que questionam o porquê do atendimento deve ser neste horário. A resposta é clara pois, a criança autista tem dificuldades nas relações afetivas e sociais e parecem viver em um universo isolado e paralelo. Tirá-la da sala de aula regular, para fazer o atendimento, seria reforçar essa característica. O contato com as outras crianças de sua faixa etária propicia o aprendizado comunicativo, social e comportamental. O relato da experiência vivenciada em 2016 pela professora com uma estudante diagnosticada com TEA comprova isso:

A criança, no ano anterior, não ficava dentro da sala de aula e tinha muita dificuldade para se relacionar com os colegas e demais funcionários da escola. Nesse ano, ela foi promovida para o segundo ano do ensino Fundamental. No primeiro dia de aula, a mãe foi levá-la e já falou que iria ficar na escola, pois não sabia como a criança reagiria à 
nova situação. Tratá-la normalmente, considerando sua especificidade, foi o ponto crucial. Ao entrar na sala de aula ela teve uma primeira interação conduzida pela docente, que começou dizendo que todos são iguais e especiais. No início, houve uma idéia contrária este pensamento entre os outros alunos que logo foi refutado com a conclusão exposta pela orientadora: "todos são especiais porque são filhos de Deus". Isso transformou o ambiente da sala de aula, favorecendo o crescimento social da criança em questão, que expôs sua satisfação através de um singelo sorriso, sendo notória que dentro dela, aquele posicionamento da professora, perante a turma, lhe incluiu afetivamente ao corpo estudantil do recinto. Talvez, sentia-se descriminada, excluída e obrigada a reagir diferente dos demais pelo peso da nomenclatura. Usando como ferramenta a pedagogia da inclusão: ensinar colocando a criança com TEA na participação de todas as atividades foi o que gerou na classe a ruptura desse paradigma de exclusão (sempre considerando os limites e necessidades especiais do aluno em questão). Após todo o envolvimento, a criança, passou a interagir com os demais alunos; a falar, brincar, correr e até a brigar com os demais colegas; comprovando a eficácia que a vivencial com a turma fornece ao seu desenvolvimento social e de também na aprendizagem. Foi por meio da observação que o discente em questão obteve êxito na aprendizagem pois, ela observava os colegas fazendo as atividades, como também exercícios didáticos, e procurava fazer da mesma forma dentro do seu limite.

O professor do Atendimento educacional especializado deve saber que o autismo é um distúrbio que afeta as capacidades de aprendizado, comunicação e adaptação. E que para iniciar o trabalho de atendimento, se faz necessário uma diagnose da história de vida da criança. Assim compreenderá a causa de alguns comportamentos e facilitará a aproximação com a criança criando um laço de amizade, afetividade e respeito. A criança autista tem sua preferência de companhia, então o professor deve viabilizar a interação para que a o mesmo sinta-se confortável e confiante aceitando os trabalhos e atividades desenvolvidas. Logo após o estabelecimento dessa relação, o professor elaborará atividades específicas, com a finalidade de observar a aceitação ou não do discente. Para o mesmo objetivo específico são usados vários recursos didáticos das mais diversas tecnologias que 
haja na sala de recursos. Posteriormente a cada atendimento realizado, são realizados relatórios e mapeamento dos avanços e das dificuldades apresentadas, que servirão de base para a elaboração e execução de um cronograma e plano de atendimento educacional especializado, avaliando a funcionalidade e a aplicabilidade dos recursos e atividades pedagógicas como: jogos, músicas, atividades na mesa educacional interativa, contagem de história, em consonância com os conteúdos programados na base curricular.

Silva e Almeida (2020, p. 63), constataram por meio de pesquisa informações claras e objetivas relacionada ao processo de ensino e aprendizagem de alunos com TEA, destacando que, "a educação de uma criança autista é uma experiência que exige do educador uma organização pedagógica direcionada ao desenvolvimento de suas habilidades e competências", sendo assim, de suma importância que no processo de inclusão o professor reconheça as dificuldades do aluno no processo educativo "e buscar a participação e o avanço de todos, trabalhando com novas práticas pedagógicas”.

Orrú (2013, p. 1708), descreve que no AEE do aluno com TEA:

É importante destacarmos que as relações sociais promovem transformações no desenvolvimento. Logo, o educando com autismo, apoiado nas relações sociais com os demais colegas, poderá desenvolver diferentes possibilidades de aprendizagem. Portanto, o foco não deve estar nos sintomas do autismo, nas deficiências e falhas, como se faz de modo acentuado nos critérios diagnósticos, mas sim nas potencialidades que podem ser desenvolvidas por um sujeito que aprende.

Entretanto, Silva e Almeida (2020, p.67) nos casos de TEA, o problema principal é a inflexibilidade, sendo que, a "ocorrência de tais manifestações não devem ser interpretada como o estado permanente da criança ou no que consiste o seu porvir", pois, trata-se de comportamentos que são esperados quando ocorre alguma mudança na rotina. Neste sentido, as autoras descrevem a importância da criança com TEA estar inserida no ambiente escolar o quanto antes, "tendo em mente que a mesma inflexibilidade que torna tão difíceis as primeiras experiências nesse ambiente poderão também promover o apego a situações que posteriormente poderão se tornar indesejáveis" (SILVA E ALMEIDA, p. 68). 
Algo também importante é o vínculo com os pais, atentos sempre a quanto avança seu filho no aprendizado e na aquisição de competências, complementando tudo isso nos lares através de exercícios e tarefas que lhes são orientadas, como continuidade do trabalho educativo da escola. $\mathrm{O}$ atendimento Educacional Especializado trabalha com o objetivo de alcançar a melhora progressiva da qualidade de vida do aluno, definindo as condutas em conjunto e envolvendo a família do autista frequentemente ao processo. O professor do AEE deve uma vez por mês se reunir com os pais para receber deles os feedbacks e ao mesmo tempo falar sobre a rotina dele em casa recebendo acompanhamento e atenção especial nas intervenções.

Com o avanço da tecnologia é comum os pais darem o celular ou tablet's as crianças, consequentemente, se fazem necessário que o professor utilize dessas e outras ferramentas em prol do desenvolvimento da criança autista. Então, ensinar e usar recursos de Tecnologia Assistiva, tais como: as tecnologias da informação e comunicação, a comunicação alternativa e aumentativa, a informática acessível, os softwares específicos, entre outros; de forma a ampliar as habilidades funcionais dos alunos, promovendo autonomia, atividade e participação. A TA no Atendimento Educacional Especializado, surge como uma ferramenta atualizada que contribui para desenvolver estratégias, serviços e recursos, tendo em vista a acessibilidade, assim como a participação autônoma da pessoa com necessidades especiais em seu percurso biopsicossocial. Como afirma Schimer et al (2007),

Fazer TA na escola é buscar, com criatividade uma alternativa para que o aluno realize o que deseja ou precisa. É encontrar uma estratégia para que ele possa fazer de outro jeito. É valorizar o seu jeito de fazer e aumentar suas capacidades de ação e interação a partir de suas habilidades. É conhecer e criar novas alternativas para a comunicação, escrita, mobilidade, leitura, brincadeiras, artes, utilização de materiais escolares e pedagógicos, exploração e produção de temas através do computador, etc. É envolver o aluno ativamente, desfiando-se a experimentar e conhecer, permitindo que construa individual e coletivamente novos conhecimentos. É retirar do aluno o papel de espectador e atribuir-lhe a função de ator. (p.31)

A criança autista quando se depara, na sala de recursos com a mesa interativa, por exemplo, se sente atraída por todo encanto e diversidade de jogos educativos da área da matemática, da história, do meio ambiente, da interação social, do português com 
alfabetização e contações de histórias que interagem com a criança. Isso estimula a imaginação através da história animada com vídeo que possibilita o autista a entender o enredo, uma vez que o mesmo tem dificuldade para compreender as informações abstratas. Os jogos estimulam o raciocínio lógico, a aprendizagem e o seu desenvolvimento. Apesar das dificuldades envolvidas no tratamento de criança com TEA, é possível usar variados aparatos como aliados na socialização, pois há muitos que precisam de mais de auxílio para desabrochar socialmente. $\mathrm{O}$ atendimento educacional especializado está cada vez mais atento ao uso das tecnologias para romper barreiras e viabilizar o desenvolvimento e aprendizagem da criança.

Sob essa perspectiva que, as ferramentas digitais facilmente acessadas hoje em dia, traz consigo a função de fornecer autonomia as crianças com TEA, quando englobadas no contexto de recursos presentes na sala de atendimento. Esse reconhecimento fiel da importância de aplicativos e outros meios digitais, que proporcionam a integração das salas do AEE ao sistema High-tech ${ }^{2}$, favorecendo a aprendizagem e ampliando as técnicas da equipe envolvida no crescimento e desenrolamento interacional da criança autismo.

A prova disto se dá pelo entendimento da adaptação social que, mediante aos esforços apresentados nas escolas inclusivas, gera na organização do coletivo que tem a intenção do término da segregação entre pessoas sem e com necessidades especiais, seja no meio da rua (através da adaptabilidade do sinal, do asfalto e entre outras partes), seja nos ambientes de trabalho que incorporam autistas no quadro de funcionários. Essa atitude corrompe o capacitismo, que se refere ao preconceito que tem como base inferiorizar o ser humano devido alguma deficiência que o mesmo possui.

O capacitismo se abrange a toda forma de preconceito sejam eles aos deficientes físicos, auditivos, visuais, mentais ou portadores de alguma síndrome que são menosprezados pelos demais seres. Esse nome vem do fato das pessoas que o cometem, acreditarem que os deficientes não vão realizar a atividade designada com êxito posta a sua limitação, porém é ai que entra a inclusão (que não se resume apenas ao território escolar,

\footnotetext{
${ }^{2}$ High-tech: de alta tecnologia; cuja tecnologia é muito avançada.
} 
mas que se estende a todas as demais áreas de convivência social); por meio do diálogo e interacionismo além do contato e orientação apresentando aos demais que, o PNE (Portado de Necessidades Especiais) consegue efetuar qualquer atividade que uma pessoa sem necessidades especiais pode fazer pois, todos possuem a mesma capacidade na realização das tarefas demandadas.

O acompanhamento durante toda a vida é crucial, não se limitando apenas aos anos iniciais de ensino. É certo que a finalidade principal do Atendimento é fornecer autonomia ao que dela usufrui, no entanto, as constantes transformações que adentram ao mundo podem causar inúmeras reações. A presença da família para o acolhimento perante qualquer novidade comportamental e intelectual, são pontos que devem permanecer no cotidiano da pessoa com Transtorno do Espectro do Autismo- TEA tendo em vista a capacidade que o autista tem em se isolar quando algo foge ao seu controle por isso uma assistência psicológica vindoura, o apoio familiar e a interação contínua devem ser atreladas as suas prioridades.

Isso não significa que o tratamento deve ser diferenciado, mas que a observância durante todo seu desenvolvimento como cidadão participante precisa está alinhada a fim de que se possam evitar danos irreparáveis a vida da criança em formação, uma vez que a sociedade se encontra, infelizmente, longe de ser um modelo de acolhimento e igualdade. Por meio disto, trabalhar o quanto antes a instituição para o recebimento, não apenas das crianças com TEA, mas qualquer uma com necessidades especiais é também preparar a classe na abordagem receptiva e na introdução do PNE no recinto, enfatizando a afetividade e a compreensão de igualdade entre todos os discentes já que são eles os adultos do futuro.

\section{CONSIDERAÇÕES FINAIS}

A importância que $o$ atendimento educacional especializado produz no desenvolvimento das crianças com TEA e outras necessidades especiais são notórias e necessárias no contexto vigente, pois o avanço depende do impacto que a educação causa 
no molde social em que a humanidade está inserida. Através deste pressuposto que ocorre a desejada quebra nos preceitos impostos pela sociedade, entra em contraste com as medidas idealizadas para as crianças com autismo, que enfrentam desde cedo dificuldades devido as características oriundas transtorno. Por meio disto, a implantação do AEE no sistema educacional de ensino na finalidade de aprimorar a vivência destas crianças e também o reconhecimento do TEA como uma deficiência, impôs ao comum a seriedade que manifestação pela inclusão agrega ao meio global. Em vista disso, o conteúdo exposto neste trabalho apresentou de forma ampla e clara o percurso substancial que, gradativamente tem de sê-la aplainado na rede de ensino visando tanto a preparação do ambiente escolar como no preparo do corpo docente e demais funcionários cujo fazem parte da instituição.

Portanto, os objetivos específicos foram alcançados sucessivamente através do desenvolvimento na qual foi delineado a contextualização do autismo por meio de uma pesquisa aprofundada, indicando a necessidade que o Atendimento Educacional Especializado concede a estruturação da instituição de ensino que dela faz uso mostrando, por meio das pesquisas, a importância que a inclusão traz para a formação da criança autista em seu ciclo social e pedagógico. Assim, traçando uma nova vertente na sociedade que rotineiramente se encontra disposta a romper com paradigmas arcaicos, abrindo espaço para a inclusão que começa na escola e reflete em todo o corpo social, enfatizando o papel da equipe multidisciplinar e dos professores especializados que por meio do ensino tem o poder de transformar o mundo.

\section{REFERÊNCIAS BIBLIOGRÁFICAS}

BRASIL, Ministério da Educação, Lei no 6.57ı, de 18 de setembro de 2008. Disponível em: http://portal.mec.gov.br/index.php?option=com_docman $\&$ view $=$ download $\&$ alias $=428$ diretrizespublicacao\&Itemid=30192\#: : text=O\%20atendimento\%20educacional\%2oespecializado\%20\%20AEE,alu nos\%2C\%2oconsiderando\%2osuas\%2onecessidades\%2oespec\% $\mathrm{C}_{3} \% \mathrm{ADf}$ icas. Acesso em o6 de junho de 202I. 
BRASIL. Ministério da Educação, 2012. Disponível em: http://portal.mec.gov.br/index.php?option=com_docman\&view =download\&alias=9936manual-orientacao-programa-implantacao-salas-recursosmultifuncionais\&category_slug=fevereiro-2012-pdf\&Itemid=30192. Acesso em: 22 de maio de 2021.

Como são organizadas as salas de recursos multifuncionais e qual o objetivo do Atendimento Educacional Especializado (AEE). Instituto Paradigma, 2013. Disponível em: https://iparadigma.org.br/pergunte/educacao-inclusiva/I66-como-sao-organizadas-assalas-de-recursos-multifuncionais-e-qual-o-objetivo-do-atendimento-educacionalespecializado-aee/.Acesso em: 22 de maio de 202I.

MARCONI,M.A; LAKATOS, Eva Maria. Técnicas de pesquisa. 4 ed. São Paulo: Atlas,1999.

SANTOS,J.C.F. Pesquisa quantitativa versus pesquisa qualitativa: o desafio pragmático. IN: SANTOS,F.J.C.F;GAMBOA,S.S. Pesquisa educacional: quantidade-qualidade. São Paulo: Cortez,1995.

SANTOS, Sônia Alves dos. BROGNOLI, Maicol de Oliveira. Transtorno do Expecto de Autismo (TEA) e o Atendimento Educacional Especializado (AEE). Revista Científica Multidisciplinar Núcleo do Conhecimento. Ano 05, Ed. II, Vol. II, pp. 79-9I. Novembro de 2020. ISSN: 2448-0959, em: https://www.nucleodoconhecimento.com.br/psicologia/transtorno SEVERINO,A.J. Metodologia do Trabalho Científico. I ed. São Paulo: Cortez, 2013 SILVA, S. F.; ALMEIDA, A. L. Atendimento educacional especializado para aluno com autismo: Desafios e possibilidades. Intl. J. of Knowl. Eng., Florianópolis,v.r,n.ı,p.6288.Disponível em https://www.nucleodoconhecimento.com.br/psicologia/transtorno, acesso: 23 de junho de 202I. 